\title{
The Multi-Energy Coupling System (MECS) Design Scheme For Campus
}

\author{
Xiaomeng $\mathrm{Yu}^{1, \mathrm{a}}$ \\ ${ }^{1}$ School of the North China Electric Power University, Baoding 071000, China; \\ a1147821514@qq.com
}

Keywords: the Multi-Energy Coupling System (MECS) CCHP electric car the cold, hot, and electric load characteristic economic benefit environmental benefit energy-conserving benefit

\begin{abstract}
This paper first distinguishes the Multi-Energy Coupling System (MECS) from the Energy Internet and the Integrated Energy System, and defines technique features of the Multi-energy Coupling System. Then, on the basis of the CCHP technical proposal and the photovoltaic configuration, a MECS design scheme which is suitable for campus is presented. Next, by studying the cold, hot, and electric load characteristic of a typical campus which is located in Hebei province, we allocate the Multi-Energy Coupling System. In addition, this paper analyses the economic benefit, the environmental benefit, and the energy-conserving benefit of the MECS.
\end{abstract}

\section{Introduction}

Nowadays, the problems such as energy shortage, environment pollution is more and more become one of the key factors which restrict the development of the world. To improve and solve these problems, experts put forward several new energy system concept, such as the Energy Internet, the Integrated Energy System and so on. In reference [1], a famous American scholar J Rifikin put forward the vision of the Energy Internet for the first time, and most studies about this concept are focus on solving the problem of energy development on the angle of Internet. The Integrated Energy System is in the process of planning, design, construction and operation, through the generation, transmission and distribution of all kinds of energy (energy supply network), conversion, storage and consumption, social comprehensive energy supply, which is formed by the Integrated System.

The Multi-Energy Coupling System (MECS), in contrast, much more from the system perspective to consider issues such as energy distribution. It mainly has the following technical characteristics: (1)

The Combined Cooling, Heating, and Power (CCHP) system. This running mode refers to the natural gas as the main energy, the high grade heat energy to generate electricity, low grade heat energy to generate heating and cooling. (2) Clean and renewable energy. Traditional CCHP system combined with renewable energy, the internal load fluctuation can be effectively regulated. (3) Electric cars. Electric vehicles in the MECS, either as an energy storage unit, and can be as a distributed power supply. It can not only greatly reduce the amount of electricity generation and energy storage device system, but also can effectively alleviate the pressure of the power grid.

\section{The MECS Design Scheme}

CCHP. The turbine-direct combustion $\mathrm{LiBr}$ absorption unit reduces the waste heat boiler, standby boiler and related auxiliary system, and greatly reduces the system cost, operation cost and maintenance difficulty. This makes the system configuration is more reasonable, and has a broader market. Thus, in view of the campus, this paper will adopt the gas turbine-direct combustion $\mathrm{LiBr}$ absorption unit.

Photovoltaic Diagram. The MECS contains an array of photovoltaic array, which receive solar energy to generate power. Photovoltaic power generation of electricity by distributor communication sent to the local load, excess electricity through the circuit to the electric car battery or feedback to power grid. 
Design Scheme. The MECS is connected to the power grid through distribution transformer. The distributed power supply system consists of photovoltaic, gas turbine and the corresponding configuration has generator, turbine-direct combustion $\mathrm{LiBr}$ absorption unit, the electric car. System with cooling load (including electric refrigeration load and the cooling load of LiBr refrigeration unit), heat load (including the heat load for heating and hot water supply), electricity load (including important pure electricity load, general pure electric load and electric refrigeration load). System of gas turbine and the turbine-direct combustion $\mathrm{LiBr}$ absorption unit constitute the CCHP system. Electric load can be supply by three directions: when the light is enough, it can be supplied by photovoltaic system, excess electricity can be transported to electric vehicles or power grid; when light is insufficient, it can be supplied by both the MECS and the power grid, which ensures the reliability of power supply.

Electric cars can be either as an energy storage unit, and can be as a distributed power supply. For the above MECS, this paper describes its energy flow relations which are shown in figure 1.

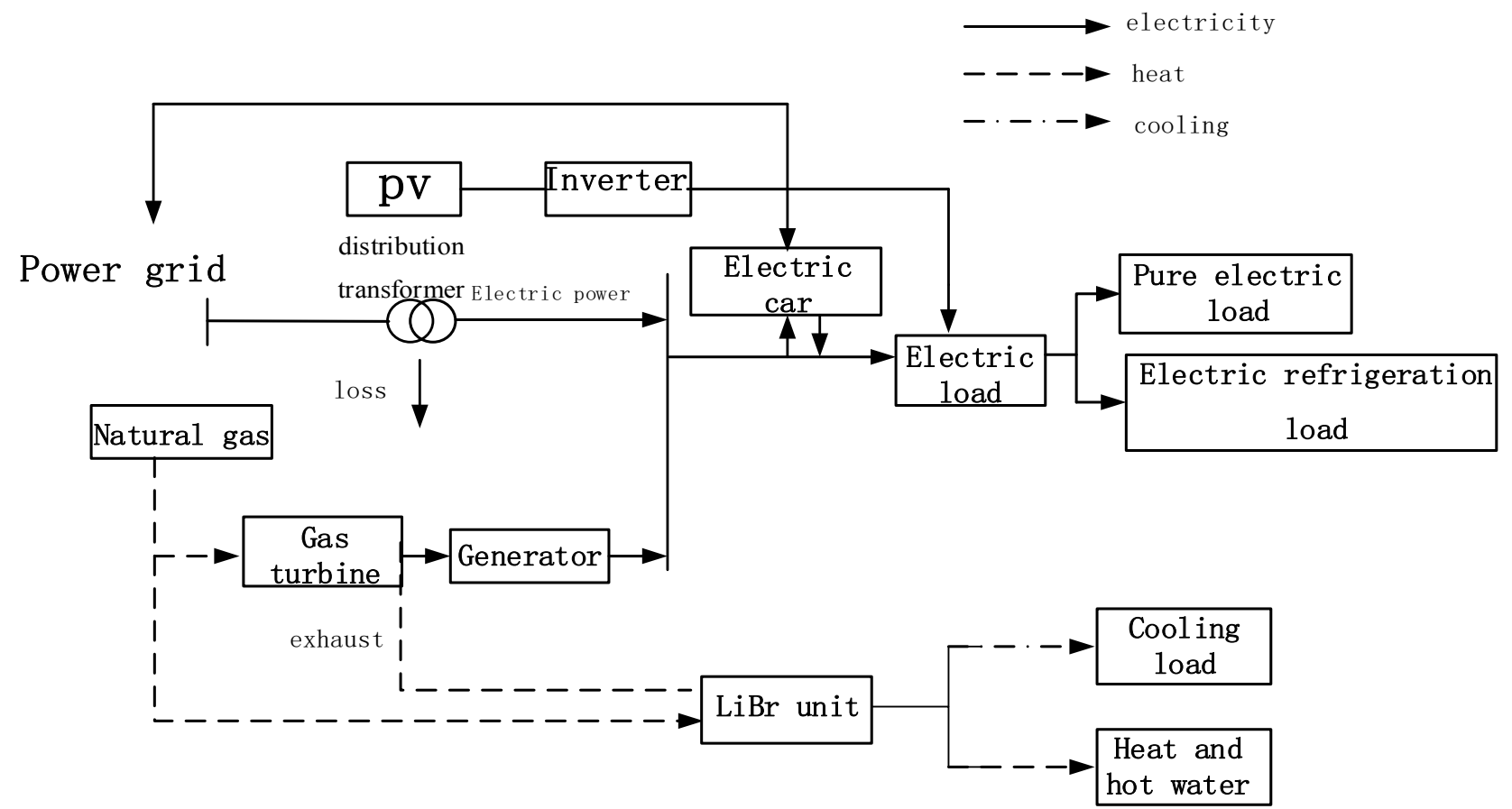

Figure 1 energy flow relations in MECS

In figure 1, visible, imaginary and imaginary point line show the energy flow directions of electricity load, heat load and cooling load respectively. The MECS use double bus power supply, since the gas turbine outlet voltage is $380 \mathrm{kV}$, it can supply the load directly. Flue gas $\mathrm{LiBr}$ unit can supply cycle through a pipeline to the teaching building and dormitory. Photovoltaic (pv) power generation system can need not set up line to supply load because it is close to the load, and the excess supply of electricity can be provided to electric cars or power grid through lines.

\section{Cold, Heat, and Electricity Load of a Campus}

In this section, this paper selects a campus in Hebei province as a typical calculation object. Since the Steady state method is simple and efficient, this paper adopt this method to calculate heat and cooling load of this campus. Due to the campus load demand situation changes with the seasons, and is closely related to students in the school, we choose typical days in different seasons to do hourly analysis. Typical day date is as follows: Spring on April 15, summer on July 1, autumn on October 15, winter on January 15.

Based on reference [2], the heat transfer coefficient of enclosure structure parameter is set to the roof is $0.87 \mathrm{w} / \mathrm{m}^{2} .{ }^{\circ} \mathrm{C}$, the window heat transfer coefficient is $6.4 \mathrm{w} / \mathrm{m}^{2} .{ }^{\circ} \mathrm{C}$, outer wall heat transfer coefficient is $1.56 \mathrm{w} / \mathrm{m}^{2} .{ }^{\circ} \mathrm{C}$, indoor temperature is $26^{\circ} \mathrm{C}$. Typical summer day's cooling load is 
calculated as shown in figure 2. In winter design day, settings are the same as above, indoor temperature is $18{ }^{\circ} \mathrm{C}$. Typical winter day's heat load is calculated as shown in figure 3 .

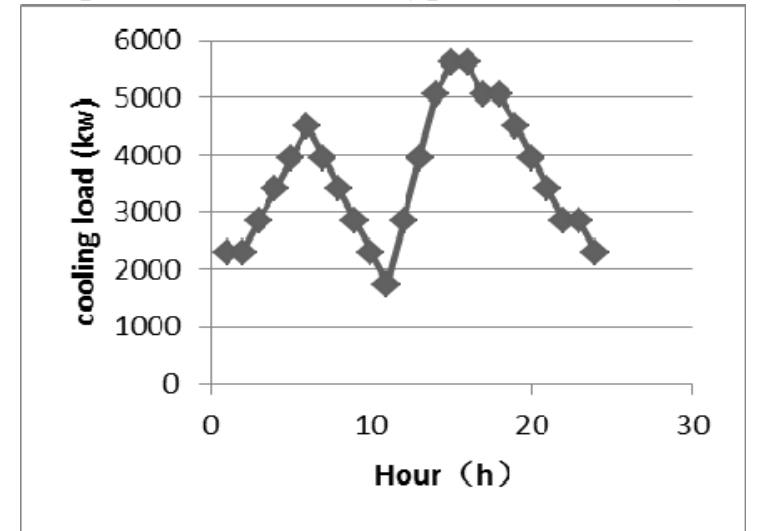

Figure 2 Typical summer day's cooling load

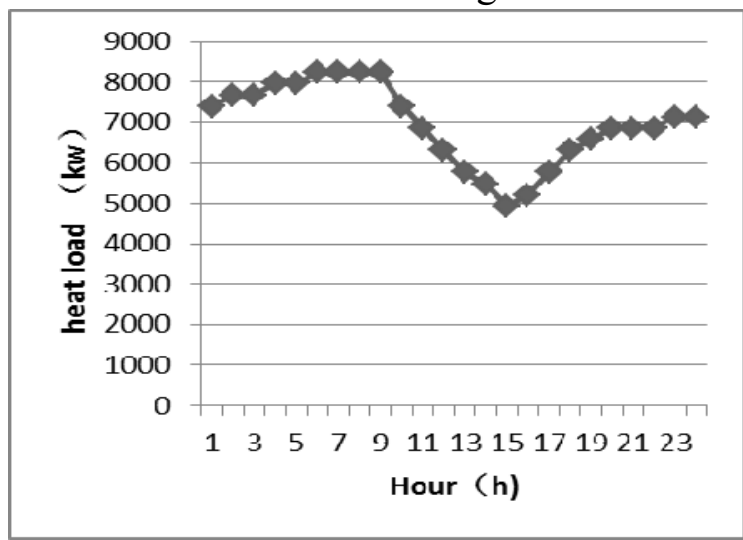

Figure 3 Typical winter day's heat load

For power load data, it can be read directly on electricity curve from the Hebei electric power company's power acquisition system, as shown in figure 4.
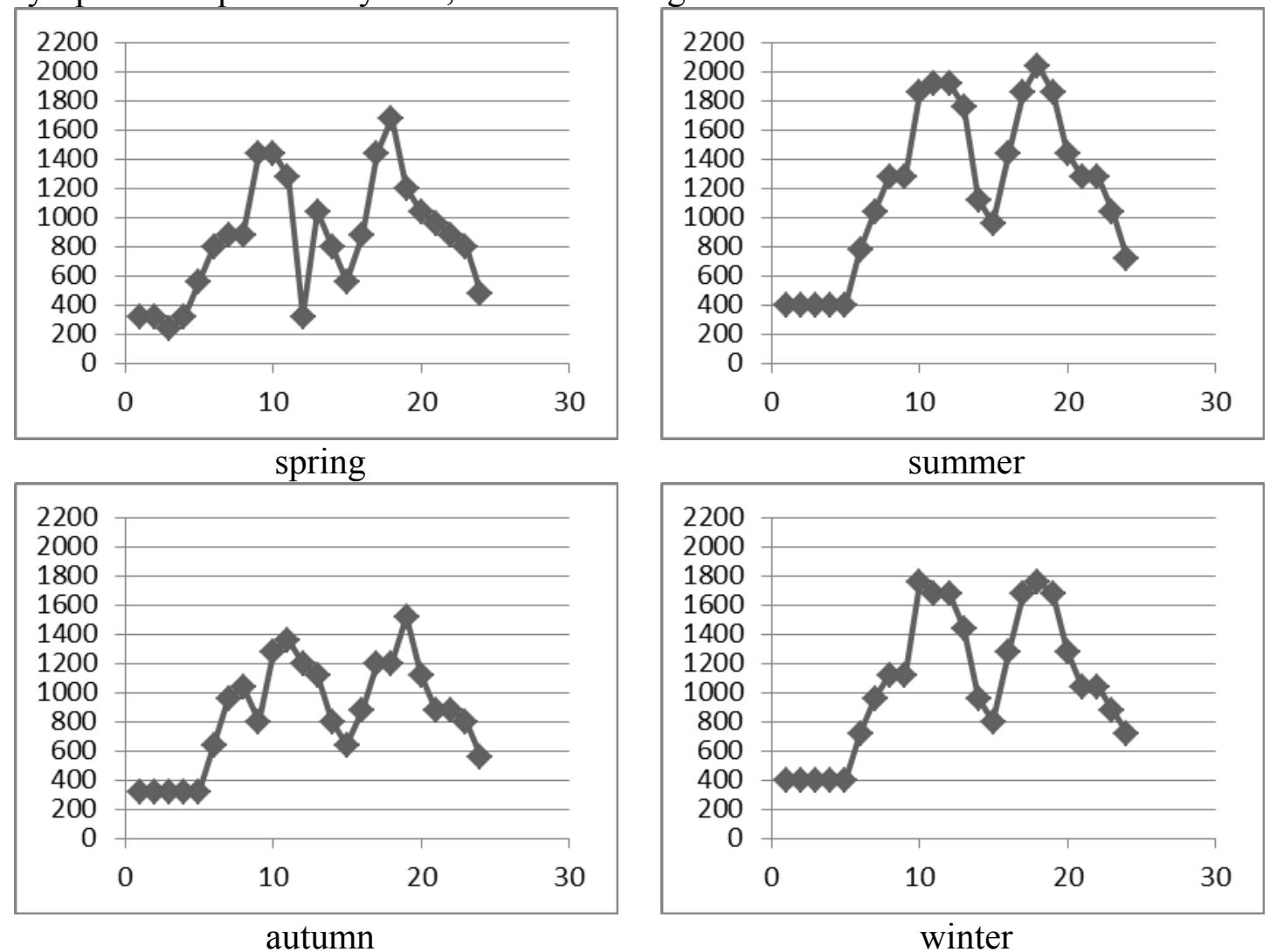

Figure 4 Typical days' electricity load

Note: the y coordinate for hourly electric load $(\mathrm{kW})$, the abscissa for time of day $(\mathrm{h})$.

From figure 4, we know: the hourly cooling load in a downward tendency in the morning and begin to rise at afternoon. Around two o'clock in the afternoon, it reaches the highest level. And the highest load is $5609.936 \mathrm{~kW}$, minimum load is $1744.5 \mathrm{~kW}$, average load is $3608.205 \mathrm{~kW}$. The head load in the night is always at a higher level, while the heating level drops in the morning and starts to reduce thernal load. It reaches the lowest level at about two o'clock in the afternoon. And the curve shows the maximum heat load of $8232.9867 \mathrm{~kW}$, average heat load of $6963.735 \mathrm{~kW}$. The highest electric load is $2040 \mathrm{~kW}$, while the minimum is $240 \mathrm{~kW}$. 


\section{System Configuration}

According to calculation, the photovoltaic panel area is $6000 \mathrm{~m}^{2}$ in this campus. And this sysem choose the SFP290W-72 polysilicon batteries $(2 \mathrm{~m} \times 1 \mathrm{~m})$ and SG50KTL inverter. And considering the adjustment of weather factor and season factor, we can get photovoltaic system's power generating capacity is $3809638.3 \mathrm{~kW}$.

Since our MECS adopt power grid supply and equipped with electric cars, we give priority to hot and cold load to select unit capacity. According to the cooling, heat, and electricity load calculated before, the MECS plans to meet in both cooling and heating average load demand, guarantee the important pure electric load of power supply reliability. Thus, a C65 gas turbine combined with BZE600 gas turbine-direct combustion $\mathrm{LiBr}$ absorption unit is adopted.

\section{System Benefits}

$>$ Economic Benefits: we use the relative payback periods (R) to evaluate the MECS's economic benefits.

$$
R=\frac{I_{M E C S}-I_{E x}}{C_{E x}-C_{M E C S}}
$$

Where $I_{E x}$ represents the MECS' initial investment cost, $I_{M E C S}$ represents the existing system's initial investment cost, $C_{E x}$ represents the existing system's yearly operation cost and $C_{M E C S}$ represents the MECS' yearly operation cost.

$>$ Environmental Benefits: we use the $\mathrm{CO}_{2}$ equivalent emission reduction ratio $\left(\eta_{\mathrm{CO}_{2} \text {.EERR }}\right)$ to evaluate the MECS's environmental benefits.

$$
\eta_{C O_{2} . E E R R}=\frac{m_{E x}-m_{M E C S}}{m_{E x}}
$$

Where $m_{E x}$ represents the $\mathrm{CO}_{2}$ equivalent emission of the exsiting system, and $m_{M E C S}$ represents the $\mathrm{CO}_{2}$ equivalent emission of the MECS.

$>$ Energy-conserving benefits: we use the prime energy saving ratio $\left(\eta_{P E S R}\right)$ to evaluate the MECS's energy-conserving benefits.

$$
\eta_{P E S R}=\frac{b_{E x}-b_{M E C S}}{b_{E x}}
$$

Where $b_{E x}$ represents the prime energy consumption of the exsiting system, and $b_{M E C S}$ represents the prime energy consumption of the MECS.

Through calculation, we find that the relative payback periods of the MECS is 4.6 which represents high economic benefits of MECS; the $\mathrm{CO}_{2}$ equivalent emission reduction ratio is $64.5 \%$ which represents high environmental benefits; and the prime energy saving ratio is $42.5 \%$ which shows high energy-conserving benefits of the MECS.

\section{Conclusion}

This paper defines technique features of the Multi-energy Coupling System: CCHP; clean and newable energy; electric cars. Then, on the basis of the CCHP technical proposal and the photovoltaic configuration, a MECS design scheme which is suitable for campus is presented. Next, by studying the cold, hot, and electric load characteristic of a typical campus which is located in Hebei province, we allocate the Multi-Energy Coupling System. In addition, this paper find the MECS is of high economic benefit, the environmental benefit, and the energy-conserving benefit. 


\section{References}

[1] Reeve Jin Jieli m. (2014). The third industrial revolution. Contemporary prosecutors, (010), 43-43.

[2] In jing hua. (2009). Based on the EETP index in hot summer and cold winter area residential building envelope thermal performance and economics research [D] (Doctoral dissertation, changsha: hunan university). 